\title{
Modeling stochastic calcium dynamics in the dendritic spines: a hybrid algorithm Georgios Kalantzis ${ }^{1}$, Yoshihisa Kubota ${ }^{1}$ and Harel Z Shouval*1,2,3
}

\author{
Address: ${ }^{1}$ Department of Neurobiology and Anatomy, The University of Texas Medical School, Houston, Texas, USA, ${ }^{2}$ Department of Biomedical \\ Engineering, The University of Texas, Austin, Texas, USA and ${ }^{3}$ Institute for Brain and Neural Systems, Brown University, Providence, Rhode Island, \\ USA \\ Email: Harel Z Shouval* - harel.shouval@uth.tmc.edu \\ * Corresponding author
}

from Seventeenth Annual Computational Neuroscience Meeting: CNS*2008

Portland, OR, USA. 19-24 July 2008

Published: II July 2008

BMC Neuroscience 2008, 9(SuppI I):P86 doi:10.1 186/I47I-2202-9-SI-P86

This abstract is available from: http://www.biomedcentral.com/I47I-2202/9/SI/P86

(c) 2008 Kalantzis et al; licensee BioMed Central Ltd.

Stochastic fluctuation plays an important role in biology. In a small subcellular compartment like dendritic spines of pyramidal hippocampal cells, the basal level of $\mathrm{Ca} 2+$ concentration ( $100 \mathrm{nM}$ ) entails six Ca2+ ions. In such a small volume, the stochastic nature of chemical reactions considerably influences intracellular signal transductions [1]. In fact, $\mathrm{Ca}^{+2}$ is an important intracellular second messenger regulating many postsynaptic enzymes which in turn trigger modifications of synaptic strength or structure. Most of these interactions are highly nonlinear. For these reasons, we need an efficient and accurate stochastic simulation method to study synaptic functions.

One solution to this problem is a stochastic simulation algorithm (SSA) developed by Gillespie for simulating spatially homogeneous chemical systems [2]. For spatially inhomogeneous system such as intracellular environments, a major modification of the Gillespie algorithm is required. For example, Bernstein [3] subdivides the simulated volume into small cells and models the diffusion of molecules between neighboring elements as a Markov transitions process treated as a special kind of "reaction". This method was shown to accurately reproduce the macroscopic limit of reaction diffusion system with cubic autocatalytic reactions. However, a much higher simulation speed is desired for practical applications. Hybrid algorithms were proposed to solve this problem $[4,5]$. In these algorithms, the reactions are partitioned into fast and slow based on the propensities and the population of the different species: the former (fast component) is simulated deterministically and the latter stochastically.

However, such a hybrid scheme becomes problematic and produces inaccurate results especially in a stiff system. For example, dendritic spines contain NMDA receptors whose kinetic transitions are relatively slow but inject fast diffusing $\mathrm{Ca} 2+$ ions into the spines which control the subsequent biochemical signaling cascades. Because of this stiffness of our system, the propensities of the "slow" subset of reactions do not change smoothly in time and consequently the fast-slow partitioning failed to describe the calcium dynamics. In this paper, we describe a novel hybrid stochastic algorithm to overcome this problem. In short, we developed a different partitioning strategy to avoid the conflicts between fast and slow systems in the simulation. We compare our results with the fully stochastic algorithm and the fully deterministic methods. Using this hybrid algorithm, we show how the stochastic fluctuations of $\mathrm{Ca} 2+$ dynamics influence the induction of synaptic plasticity.

\section{References}

I. Shouval HZ, Kalantzis G: Stochastic properties of synaptic transmission affect the shape of spike time dependent plasticity curves. I Neurophysiol 2005, 93:1069-1073.

2. Gillespie DT: A general method for numerically simulating the stochastic evolution of coupled chemical reactions. J Comput Phys 1976, 22:403.

3. Bernstein D: Simulating mesoscopic reaction-diffusion systems using the Gillespie algorithm. Phys Rev E 2005, 7 1:04 I I 03. 
4. Chiam KH, Tan C, Bhargava V, Rajagopal G: Hybrid simulations of stochastic reaction-diffusion processes for modeling intracellular signaling pathways. Phys Rev E 2006, 74:51910.

5. Alfonsi A, et al.: Adaptive simulation of hybrid stochastic and deterministic models for biochemical systems. ESAIM Proceedings 2005, I4:I-13.

Publish with Bio Med Central and every scientist can read your work free of charge

"BioMed Central will be the most significant development for disseminating the results of biomedical research in our lifetime. " Sir Paul Nurse, Cancer Research UK

Your research papers will be:

- available free of charge to the entire biomedical community

- peer reviewed and published immediately upon acceptance

- cited in PubMed and archived on PubMed Central

- yours - you keep the copyright

Submit your manuscript here:

http://www.biomedcentral.com/info/publishing_adv.asp 